\title{
"Educar para alteridade": o ensino de História da Shoah e o uso dos testemunhos audiovisuais da USC Shoah Foundation
}

\author{
PALMEIRA, Alyne Nathálier da Silva (Brasil, Pernambuco, Recife) ${ }^{1^{*}}$ \\ SCHURSTER, Karl (Brasil, Pernambuco, Recife) ${ }^{1}$ \\ ${ }^{1}$ Universidade de Pernambuco \\ ORCID ID: https://orcid.org/0000-0002-1403-5808* \\ ORCID ID: https://orcid.org/0000-0002-1363-119X
}

\begin{abstract}
Resumo
Este trabalho, sob a luz teórica da História do Tempo Presente, propôs-se a construir uma análise do Ensino de História da Shoah, mais especificamente a partir dos materiais didáticos audiovisuais da USC Shoah Foundation Institute for Visual History and Education, expandindo a pesquisa acadêmica brasileira no campo de estudos denominado "Pedagogia de Ensino dos Traumas Coletivos". Buscou-se discutir o conjunto de materiais escolhidos, que incluem testemunhos de sobreviventes da Shoah, apropriando-se de uma análise de conteúdo. Foi estabelecido o que esses materiais elucidam sobre o ensino dessa temática, problematizando seus métodos e objetivos, bem como sobre o próprio papel do professor como ferramenta desse ensino. Partindo dessa perspectiva, o Ensino de História da Shoah estabelece-se como uma ferramenta possível no combate ao fascismo, na negação de teorias revisionistas e ainda no entendimento de uma nova cosmovisão acerca dos valores morais, éticos e jurídicos da sociedade no pós-guerra.
\end{abstract}

Palavras-chave

Shoah. Ensino de História. Traumas Coletivos.

\section{"Educating for alterity": Shoah History Teaching and use of USC Shoah Foundation audiovisual testimonies}

\begin{abstract}
This work, in the theoretical light of the History of Present Time, proposed to construct an analysis of the History Teaching of the Shoah, more specifically from the audiovisual materials of the USC Shoah Foundation Institute for Visual History and Education, expanding the Brazilian academic research in the field of studies called "Teaching Pedagogy of Collective Traumas". We will try to discuss the set of materials chosen, which include testimonies of survivors of the Shoah, appropriating a content analysis. It was established what these materials elucidate on the teaching of this subject, problematizing its methods and objectives, as well as about the proper role of the teacher as a tool of this teaching. From this perspective, Shoah's History Teaching establishes itself as a possible tool in the fight against fascism, in the negation of revisionist theories, and in the understanding of a new worldview about the moral, ethical and juridical values of society in the post-war.
\end{abstract}

\section{Keywords}

Shoah. History teaching. Collective Traumas.

Educação \& Formação, Fortaleza, v. 5, n. 13, p. 195-214, jan./abr. 2020 DOI: https://doi.org/10.25053/redufor.v5i13.1123 


\title{
"Educar para alteridad": la enseñanza de Historia de Shoah y el uso de los testimonios audiovisuales de USC Shoah Foundation
}

\begin{abstract}
Resumen
Este trabajo, bajo la luz teórica de la Historia del Tiempo Presente, se propuso construir un análisis de la Enseñanza de la Historia de la Shoah, más específicamente a partir de los materiales didácticos audiovisuales de la USC Shoah Foundation Institute for Visual History and Education, ampliando la investigación académica brasileña en el campo de estudios denominado "Pedagogía de Enseñanza de los Traumas Colectivos". Se buscó discutir sobre el conjunto de materiales escogidos, que incluyen testimonios de sobrevivientes de la Shoah, apropiándose de un análisis de contenido. Se estableció lo que estos materiales elucidan sobre la enseñanza de esta temática, problematizando sus métodos y objetivos, así como sobre el propio papel del profesor como herramienta de esa enseñanza. A partir de esa perspectiva, la Enseñanza de Historia de la Shoah se establece como una herramienta posible en el combate al fascismo, en la negación de teorías revisionistas y aún en el entendimiento de una nueva cosmovisión acerca de los valores morales, éticos y jurídicos de la sociedad en el post período de la guerra.
\end{abstract}

Palabras clave

Shoah. Enseñanza de Historia. Traumas Colectivos.

\section{INTRODUÇÃO}

A palavra "Shoah", vinda do hebraico, que significa aniquilação/catástrofe, é o termo mais comumente referido ao genocídio dos judeus da Europa, especialmente desde o filme de Claude Lanzmann de 1985 - Shoah -, tendo sido incluído na declaração de independência de Israel em 1948. No que se refere à pesquisa histórica sobre a Shoah, esta experimentou um crescimento durante mais de meio século, a ponto de ser quase impossível para os historiadores terem uma visão abrangente que seja ao mesmo tempo suficientemente detalhada e/ou completa. O campo de estudo que a constitui (Holocaust Studies), em que se discutem problemáticas relacionadas ao tema, entre elas os "limites de representação da Shoah", é caracterizado por sua abertura e dinamismo. A geração de León Poliakov ${ }^{1}$, Raul Hilberg ${ }^{2}$ e Saul Friedländer ${ }^{3}$ lançou as bases dos estudos acerca desse fenômeno.

1 Poliakov, importante historiador da Shoah, ganhou o prêmio Anisfield-Wolf Book Award for Nonfiction em 1975, com sua obra The aryan myth: a history of racist and nationalistic ideas in Europe (O mito ariano: uma história de ideias racistas e nacionalistas na Europa).

Hilberg foi um historiador que escreveu sua tese de doutorado sobre a burocracia por trás da perpetração da Shoah e ganhou prêmios como o Anisfield-Wolf Book Award for Nonfiction em 1968,

Educação \& Formação, Fortaleza, v. 5, n. 13, p. 195-214, jan./abr.

2020 DOI: https://doi.org/10.25053/redufor.v5i13.1123 
Como a queda de Roma ou a Revolução Francesa, a Shoah é um daqueles eventos históricos que representam uma era. Sua complexidade provoca, ainda hoje, questionamentos acerca de suas escolhas morais e raciocínio moral, bem como sobre o lado mais sombrio da natureza humana e sobre a imoralidade da indiferença. Foi diante dessas indagações e da necessidade de entender as grandes crises do século XX que a História, como campo de estudos, foi dimensionada, possibilitando um papel crítico crucial em relação às estruturas dominantes de pensamento, um sinal de mudança na concepção da historiografia e na relação da sociedade com sua história.

O professor historiador Yehuda Bauer, presidente honorário da Aliança Internacional de Recordação do Holocausto de 31 nações-Estados, resumiu o problema em seu escrito Reflexiones sobre el Holocausto (2008) quando percebeu que a Shoah é muitas vezes transformada em lições vagas do perigo de ódio ou preconceito às custas de realmente tentar entender as razões e motivações do genocídio. O ensino eficaz sobre a Shoah deve proporcionar conhecimento e compreensão substantivos, desafiar equívocos populares e enfrentar questões difíceis e profundas.

É geralmente aceito que as escolas devem se esforçar para imbuir os estudantes com habilidades de pensamento, e tais habilidades são mais bem ensinadas e reforçadas quando apresentadas no contexto do assunto, e não como lições isoladas sobre o pensamento. Émile Durkheim, o primeiro defensor de uma educação moral, identificou como fundamentais os valores que sustentam a dignidade humana e a proteção da vida. Ele considerou ainda que era da responsabilidade das escolas reforçar esses valores (DURKHEIM, 2008). Essas questões estão no cerne de qualquer currículo de ensino sobre a Shoah e que pode facilmente servir como um trampolim para discussões sobre justiça, direitos humanos, sobrevivência, tolerância e responsabilidade cívica na atualidade.

Um estudo de campo da educação sobre a Shoah em salas de aula do ensino médio, realizado em 2004, identifica três lentes pelas quais as unidades poderiam ser

com sua obra The destruction of the European Jews (A destruição dos judeus da Europa). Foi homenageado também com o National Jewish Book Award for Holocaust em 1986 pela mesma obra.

Friedländer é um historiador israelense e atual professor de história da Universidade da Califórnia. Escreveu obras importantes para o estudo do Nazismo e da Shoah, sendo homenageado pelo National Jewish Book Award for Holocaust em 1997 por sua obra Nazi Germany and the Jews: the years of persecution, 1933-1939 (Alemanha nazista e os judeus: os anos de perseguição, 1933-1939). Outras obras importantes incluem The years of extermination (Os anos de extermínio), ganhadora do prêmio Leipzig Book Fair Prize de não ficção.

Educação \& Formação, Fortaleza, v. 5, n. 13, p. 195-214, jan./abr. 2020 DOI: https://doi.org/10.25053/redufor.v5i13.1123 
ensinadas: particular à universal, insular à expandida e trágica à redentora (SCHWEBER, 2004). "Particular" ou "universal" e "insular" ou "expansivo" estão um pouco interligados na escala maior do debate que trata da singularidade da Shoah. Aqueles que são considerados particulares preferem enfatizar a singularidade do sofrimento judaico e antissemitismo prevalente durante o regime nazista, acreditando que o foco da Shoah deve estar centrado no sofrimento dos judeus, mas reconhecem suas implicações universais. Os universalistas, por outro lado, preferem que a Shoah seja ensinada como um representativo da natureza universal da dor, do sofrimento e das lições inerentes a ela. Eles veem a Shoah como uma oportunidade para construir uma estrutura moral universal (DAVIES, 2000). O fato de que apenas porque não se pode compreender plenamente as atrocidades da Shoah não é justificativa para ignorar sua oportunidade de educação em todo o espectro de direitos humanos e outras questões morais.

Ao preparar uma unidade, ou curso de estudo, sobre a Shoah, pode-se ver que há muito a considerar e ainda mais a saber. No entanto, através da devida diligência, os professores podem proporcionar aos seus alunos uma oportunidade de aprendizagem baseada em questionamento, destacando aspectos do comportamento humano que afetam todas as sociedades, como o potencial de violência extrema e abuso de poder; os papéis que o medo, a pressão, a indiferença, a ganância e o ressentimento podem desempenhar nas relações sociais e políticas; os perigos do preconceito, discriminação e desumanização, a fim de desenvolver um senso de responsabilidade pela vida do outro. Seguindo as diretrizes estabelecidas para os professores e avaliando os recursos adequados à prática pedagógica, é possível construir uma unidade de estudo que permita aos alunos desenvolverem uma compreensão da Shoah em um nível mais profundo, que permite obter algumas percepções sobre as ideias, crenças e circunstâncias presentes na Alemanha nazista entre 1933 e 1945.

A fim de alcançar um nível de preparação para os estudantes se tornarem membros de uma sociedade plenamente funcionais e engajados, eles precisam ter uma compreensão de onde o mundo tem estado, do que o pior lado da humanidade pode fazer se não for controlado. Isso inclui a compreensão sobre o que acontece quando nosso senso de responsabilidade para com o outro, pessoalmente, culturalmente e na comunidade, rompe-se.

Educação \& Formação, Fortaleza, v. 5, n. 13, p. 195-214, jan./abr. 2020 DOI: https://doi.org/10.25053/redufor.v5i13.1123 
Ensinar a Shoah é ensinar aos educandos que isso é evitável e que não se deve levar uma vida de apatia, mas se envolver com o mundo de maneira positiva. Portanto, dar força e dignidade à reflexão sobre a Shoah não pode se limitar ao dia da memória, por exemplo, mas deve ser abordado dentro de um caminho orgânico de base ampla que conecta a questão ao seu contexto contemporâneo, especialmente à questão da alteridade, salvaguardando a singularidade do evento, mas trazendo-o de volta a um nível mais amplo no projeto nazista de destruição da diversidade. Afinal, dentro das escolas, existe uma variedade de crenças, etnias, gêneros, que precisam não apenas ser reconhecidos, mas também sentidos como tal. Nosso conhecimento acerca do outro é falível e finito. Isso, no entanto, não diminui nossa capacidade de nos relacionar e assumir responsabilidade por eles.

Dentro de um testemunho, então, os discentes são capazes de se concentrar nesse evento em um nível micro, evitando a noção abstrata de seis milhões de pessoas e o que isso realmente significa: humanizando a Shoah, colocando um rosto nela, o rosto de uma pessoa que experimentou a política genocida, é possível articular essa história, a capacidade de tomar o todo e deixá-lo jogar na face do indivíduo parece, em última análise, dar-Ihes uma oportunidade de fazer algum sentido do que é a Shoah. É a partir das histórias individuais dos seres humanos que as pessoas constroem significados ao se envolverem com o mundo que estão interpretando. Interpretação é essencial para uma compreensão da experiência e a experiência inclui interpretação. Por meio disso, as pessoas desenvolvem uma lente através da qual elas veem o mundo.

\section{2 “USE YOUR VOICE”: O USO DOS TESTEMUNHOS AUDIOVISUAIS EM SALA DE AULA}

No período imediato do pós-guerra, a ausência da Shoah na consciência e na educação específica dela significavam que os contos de sobreviventes judeus eram vistos apenas como parte de histórias gerais que surgiram da Segunda Guerra Mundial. Como os testemunhos de sobreviventes, mais notavelmente aqueles publicados por Primo Levi e Elie Wiesel, tornaram-se cada vez mais populares, a demanda por sobreviventes para desempenhar um papel ativo na educação do Holocausto aumentou. O envolvimento de sobreviventes na educação aumentou particularmente durante o final dos anos 80 e 90 . 
Esses relatos comportam-se como vetores em contextos educativos, tanto formais como informais, em sala de aula, nos museus e em visitas aos memoriais. Porém, a necessidade de debater sobre a Shoah sem recorrer a sobreviventes ou outras testemunhas que consigam ir às salas de aula e debater com os alunos já se tornou uma realidade no meio educativo em quase todos, senão todos, os países. Os sobreviventes mais jovens possuem agora 70 ou 80 anos, e vários, ou a maior parte, são desconhecidos e não guardam memórias dos campos ou dos movimentos de resistência. Portanto, essa forma de ensino passa a ser substituída por outra que se pareça tanto quanto possível com a experiência de ouvir pessoalmente um sobrevivente.

Dentro desse cenário, relatos de pessoas que viveram e passaram por um trauma como o genocídio e outras atrocidades ajudam os alunos a compreenderem mais profundamente as dimensões humanas e desumanas de momentos importantes da história. Eles complementam 0 que se aprende com os historiadores e fontes secundárias, oferecendo perspectivas únicas sobre as situações difíceis e, às vezes, impossíveis que os indivíduos foram forçados a enfrentar durante momentos de violência e injustiça coletivas.

Existem extensas coleções de relatos orais disponíveis para uso, total ou em parte, em sala de aula. A USC Shoah Foundation Institute for Visual History and Education e outras instituições tornaram esse ensino possível. Fundada em 1994 por Steven Spielberg, seu objetivo era filmar histórias de sobreviventes e torná-las disponíveis para fins educacionais para gerações posteriores. Desenvolvendo uma plataforma chamada IWitness, a fundação propôs acesso a uma parte dos arquivos completos do Instituto através de atividades que auxiliam o currículo existente em várias áreas, incluindo estudos sociais, governo, língua estrangeira, história mundial e educação de caráter. A missão com esse recurso é incentivar os professores a ensinar efetivamente a Shoah, bem como as lições morais e cívicas relacionadas. Além de conter documentos primários, cada lição contém clipes de testemunhos específicos do arquivo. Recomenda-se ensinar a temática através de um quadro individualizado, a fim de transmitir a mensagem de que isso aconteceu com pessoas reais, que viveram vidas como a dos estudantes (ECHOES AND REFLECTIONS, 2005).

Esses testemunhos, é certo, precisam ser inseridos nos currículos e localizados em seu contexto histórico como parte da narrativa histórica e assegurados em uma 
documentação adequada. Ao entender que a história tem um impacto direto sobre a vida das pessoas e suas comunidades, que eles pessoalmente desempenham um papel na história, tem-se uma base de entendimento dos lugares de memória para sociedade do presente, tendo em vista que o ensino da Shoah é realizado pela memória da vítima. A maioria dos sobreviventes que deram seus testemunhos foram crianças ou adolescentes durante a Shoah. Isso permite aos alunos se identificarem com histórias de uma perspectiva juvenil e se envolverem com a história em um nível mais pessoal, através do meio mais adaptado à sua realidade virtual: o vídeo. "O uso de recursos audiovisuais promove uma ruptura nos processos educacionais pautados nessa linhagem tradicional" (ECHOES AND REFLECTIONS, 2005).

Um dos materiais disponibilizados pela plataforma da IWitness chama-se Lala / Reflections on Prejudice ${ }^{4}$. Assim como os demais materiais elaborados pela USC Shoah Foundation, essa lição busca não só ensinar o que foi a Shoah, mas também compreender o impacto que os eventos históricos de genocídio e traumas coletivos têm sobre os indivíduos, as comunidades e a sociedade como um todo. Lala é o testemunho de um sobrevivente da Shoah chamado Roman Kent, em forma de animação e vídeo em ação de 360ํ, que compartilha a história de seu tempo na Polônia ocupada pelos nazistas com sua cadela Lala. Esse recurso é destinado a alunos do nível 5 ao 6 da elementary school, que no Brasil equivale ao $5^{\circ}$ e 6ํao ano do Ensino Fundamental (crianças de 10 a 12 anos de idade). Através da visualização guiada do testemunho audiovisual dos sobreviventes da Shoah, os estudantes refletem a respeito do impacto do preconceito sobre os indivíduos e sobre a capacidade de resiliência em face da opressão.

O filme de realidade virtual é uma mistura de animação e vídeo live-action de $360^{\circ}$ do sobrevivente da Shoah. Roman Kniker, nascido em Lodz - Polônia, em 18 de abril de 1929, filho de Emmanuel Kniker e Sonia Kniker e irmão de Leon Kniker. Em 1939, logo após os alemães invadirem a Polônia, Roman e sua família foram expulsos de sua casa e tiveram que se mudar para um quarto vazio na fábrica de seu pai que havia sido confiscada, mas não duraram muito tempo por lá. Eles foram então enviados para o gueto de Lódz, onde as condições eram severas. No outono de 1944, o gueto foi liquidado e a família foi deportada para Auschwitz-Birkenau. Para ser transferido, Roman

${ }^{4}$ USC SHOAH FOUNDATION. Lala / Reflections on Prejudice (K-2). Disponível em: https://iwitness.usc.edu/sfi/activity/detail.aspx?activityid=3977\&retainfilter=true. Acesso em: 2 jan. 2019.

Educação \& Formação, Fortaleza, v. 5, n. 13, p. 195-214, jan./abr.

2020 DOI: https://doi.org/10.25053/redufor.v5i13.1123 
e seu irmão Leon disseram que eram comerciantes e foram enviados para Gross-Rosen e, mais tarde, para Flossenburg.

Durante uma marcha da morte a caminho de Dachau, eles foram libertados pelo exército dos Estados Unidos da América (EUA). Os irmãos então viajaram para a Suécia, onde se reuniram com suas irmãs em um hospital em Lubeck. Em junho de 1946, Roman e Leon imigraram para os EUA. Após a faculdade, os irmãos se mudaram para Nova lorque e mudaram seu sobrenome para Kent, porque era mais fácil de pronunciar. Roman conheceu sua futura esposa, Hannah, em Nova lorque, e eles se casaram em 1957. Roman se envolveu na educação sobre a Shoah em abril de 1996, quando concedeu sua entrevista para a Fundação, sendo fundamental na criação de Children of the Holocaust ${ }^{5}$, um documentário dedicado à memória das crianças que morreram durante a Shoah.

O material de ensino é acompanhado por uma minilição para preparar os alunos para a visualização de Lala. Recursos adicionais, incluindo clipes, links e uma atividade da Info Quest sobre Kent, também estão disponíveis. O objetivo da aprendizagem descrito pela atividade é: "[...] refletir sobre o impacto do preconceito e da capacidade individual de resiliência em face da opressão, demonstrar compreensão e síntese da informação extraída do testemunho audiovisual e traçar conexões com suas próprias vidas" (USC SHOAH FOUNDATION. Lala/Reflections on Prejudice).

Toda a abordagem da lição de Lala é dividida em três partes. A primeira parte, intitulada de Prejudice and Its Impact on Individuals, é destinada à preparação dos estudantes para os testemunhos que irão ser apresentados. São planejadas perguntas como: "1) O que podemos aprender com o passado? 2) Qual é o impacto do preconceito e do ódio sobre indivíduos e sociedades? 3) O que é resiliência e como podemos desenvolvê-la? 4) Que tipo de informação o testemunho audiovisual daqueles que experimentaram história, como a Shoah, fornece-nos sobre o período de tempo que outras fontes não conseguem?".

5 Children of the Holocaust (2014) é uma série produzida pela Fettle Animation em conjunto com a BBC Learning. Capturando as vidas de seis pessoas que foram perseguidas quando crianças durante 0 regime nazista - colocadas em campos de concentração, separadas de seus pais, enviadas para o exterior ou testemunhando brutalidade durante a Kristallnacht -, a série oferece uma visão íntima dos efeitos a longo prazo da Shoah.

Educação \& Formação, Fortaleza, v. 5, n. 13, p. 195-214, jan./abr. 2020 DOI: https://doi.org/10.25053/redufor.v5i13.1123 
A atividade prossegue indicando que se projete a palavra "preconceito" no quadro para que os alunos pensem calmamente sobre o que vem à mente quando leem a palavra. É então que eles são instigados a refletirem sobre algum momento no qual sofreram preconceitos ou foram levados a se sentir diferentes e excluídos por causa de uma característica pessoal, por causa de seu pertencimento a um grupo ou por causa de suas crenças (ou alguém que eles conhecem). Posteriormente pede-se que o professor levante mais algumas perguntas: 1) Se você teve ou observou uma experiência com preconceito, como isso fez você ou a pessoa se sentir? 2) Se você não teve ou observou uma experiência com preconceito, como você acha que isso faria você se sentir? 3) Por que você acha que eles/vocês foram alvos? 4) Como a experiência com o preconceito afetou você (eles)? 5) O que você acha que ajudou você (eles) a superar a experiência ou a lidar com isso? As respostas dos alunos demonstrarão as várias maneiras pelas quais os estudantes e os indivíduos lidam com o preconceito e a exclusão - o que está no centro da resiliência.

Após a discussão, seria compartilhada uma minibiografia dos sobreviventes, apresentadas nos videoclipes dessa lição. Numa primeira visualização, os testemunhos compilados de Kent e mais uma sobrevivente, Eva Freedman ${ }^{6}$, devem ser reproduzidos até o final, sem interrupções. Ao fim dos vídeos, propõe-se que os alunos devam pensar em silêncio sobre o que se destacou para eles nas histórias que os sobreviventes contam. E então o clipe é reproduzido pela segunda vez, para que agora os discentes prestem atenção à linguagem corporal, expressões faciais, voz e tom, bem como ao fundo e data / período de tempo de quando o depoimento foi dado. Durante essa segunda visualização, os estudantes receberiam dois desenhos de carinhas, uma triste e outra feliz, e seriam instruídos a utilizá-las partindo da percepção das ações, palavras e sentimentos que seriam justos ou injustos. Eles deveriam compartilhar a "cara feliz" quando Eva compartilha algo que acham que é justo e utilizar o "rosto triste" quando ouvi-la dizer algo que parece injusto. Depois de recolher reações dos estudantes para o clipe de testemunho, sugere-se explicar aos educandos que muitas vezes as pessoas julgam os outros por causa de suas diferenças.

6 Eva Freedman, nascida em julho de 1934 em Bratislava, Checoslováquia, conta sua experiência no esconderijo de um prédio de apartamentos, movendo-se entre um quarto no andar de cima e um porão por cerca de onze meses junto com sua família.

Educação \& Formação, Fortaleza, v. 5, n. 13, p. 195-214, jan./abr. 2020 DOI: https://doi.org/10.25053/redufor.v5i13.1123 
A sequência de visualização indicada pelo material fornece aos alunos exemplos de preconceito e ódio na Polônia antes da guerra (Roman Kent) e na Checoslováquia durante a guerra (Eva Freedman). São testemunhos curtos, com cerca de três minutos cada, onde as experiências de vida de cada sobrevivente, mesmo estando em diferentes lugares da Europa, cruzam-se no sentimento de impotência frente à barbárie projetada pela política genocida na Alemanha de 1933-1945.

A segunda parte da lição, intitulada Lala - A Virtual Reality Experience, é quando os alunos verão o filme de realidade virtual de seis minutos que usa ação ao vivo e animação para contar a verdadeira história do animal de estimação de Roman Kent, Lala, e como Lala deu à família Kent uma sensação de continuidade em suas vidas e fortaleceu a resiliência da família diante de condições terríveis no gueto ${ }^{7}$. Uma mensagem importante na história é a crença de Roman de que "o amor é mais forte que o ódio". O vídeo dura cerca de seis minutos e a história é produzida em cima da experiência mais marcante da vida de Kent, no sentido de ter esperança em meio a todo o horror da guerra.

O vídeo é narrado por Kent junto às imagens de animação. O sobrevivente conta que, mesmo depois de sua família ter sido expulsa de Lódz, onde moravam, eles levaram junto a cadela Lala para o esconderijo na antiga fábrica têxtil do pai de Kent. $\mathrm{Na}$ época, Lala andava com seus filhotes; com a chegada dos nazistas no esconderijo, Kent e sua família foram levados a uma área residencial, sendo forçados a deixarem tudo para trás, incluindo Lala. Com 10 anos de idade durante a caminhada para o gueto, Kent afirma que não entendia bem as implicações do que estava acontecendo, nem se preocupava muito, pois estava com seus pais. A mente de Kent estava única e exclusivamente preocupada com Lala.

Durante uma noite qualquer no gueto na Polônia, enquanto chovia muito, Kent e sua família ouviram a chegada de Lala, inesperadamente. Ele afirma não saber como ela os encontrou, mas na manhã seguinte Lala sumiu novamente. Todas as noites a cadela aparecia para vê-los e pela manhã retornava para seus filhotes, essa era a rotina de Lala. Kent afirma: "Nenhum arame farpado, nenhuma arma, nada colocado no caminho podia impedir essa cachorrinha de nos amar, de vir para nós e depois retornar para seus filhotes. Eu queria que, às vezes, as pessoas fossem mais como Lala".

7 USC SHOAH FOUNDATION. Lala / Reflections on Prejudice (K-2). Disponível em: https:/iwitness.usc. edu/sfi/activity/detail.aspx?activityid=3977\&retainfilter=true. Acesso em: 2 jan. 2019. 
Após alguns dias nessa rotina, um aviso apareceu no gueto: de que todos os cachorros cujos donos eram judeus tinham que ser entregues aos alemães. Estes tinham o nome de todas as famílias que possuíam cachorro. Segundo Kent, as consequências do não cumprimento eram severas. Em um dia normal, Lala sempre se animava para dar uma volta com Kent e sua família, entretanto, na noite em que ela estava prestes a ser levada para os alemães, Lala instintivamente sabia que havia algo de errado e se escondeu. Ela se recusou a andar por si mesma e tiveram que carregá-la. Depois disso, Lala nunca mais foi vista por Kent e a família dele. "Mas, ainda hoje, depois de tudo, eu ainda acredito no que Lala me ensinou [...]; os nazistas já desapareceram faz muito tempo, no entanto, neste exato momento, enquanto eu falo com você, eu posso sentir o amor de Lala. Lala ainda vive no meu coração" (KENT, R.).

Na última parte da lição, intitulada Reflections on Prejudice, os alunos deveriam discutir em torno de algumas questões: 1) Você acha que o significado de "amor é mais forte que o de ódio"? 2) As histórias que você ouviu e assistiu nesta lição ajudaram você a pensar de maneira diferente ou, de alguma forma, mudaram sua opinião sobre o preconceito? Se sim, como? Se não, por que não? 3) Você acha que esta lição influenciará como você interage com pessoas diferentes de você no futuro? Se sim, como? Se não, por que não?

É perceptível o intuito da lição de, através de uma análise histórica profunda e responsável, permitir que os alunos possam desenvolver um sentido de contextualização histórica a fim de engajar-se num estado de empatia. A lição envolve uma conexão afetiva com a situação enfrentada por outra pessoa, que é moldada por nossa compreensão cognitiva da perspectiva da pessoa e as circunstâncias extenuantes que a cercam. À medida que os alunos refletem sobre isso em figuras históricas e chegam a entender que a perspectiva humana está enraizada no contexto social, político, econômico e cultural de sua época, essa compreensão proporciona a vantagem de analisar e avaliar suas próprias crenças e ações e as dos outros que se encontram no presente.

O testemunho completo de Kent, que é disponibilizado pela USC Shoah Foundation em seu acervo, traz duras informações sobre esse evento tão perverso. Dessa forma, a adaptação da história desse sobrevivente, feita em forma de animação, traz à tona a discussão sobre como é possível ensinar a crianças tão jovens este trágico evento sem traumatizá-las. Essa adequação à idade delas é essencial para que o 
objetivo do estudo seja atingido. Educar as crianças sobre a Shoah, nessa idade tão jovem, envolve principalmente dar sentido ao que elas já ouviram e experimentaram como parte integrante de uma sociedade multiétnica.

Portanto, como acontece com qualquer tema sombrio da história da humanidade, ao qual as crianças podem ser expostas, a ideia é dar a elas as informações de que precisam para gerar um sentimento de responsabilidade afetiva pela vida do outro. Toda a abordagem desse tema pode ser mantida de forma espiral, ou seja, de modo que a cada ano o aluno seja apresentado a mais e mais sobre o assunto, já que a carga emocional de um evento como a Shoah é imensa. Uma das coisas mais importantes para entender é que aprender sobre a Shoah deve ocorrer em um quadro de um processo educacional. Os educadores devem estar constantemente focados no valor da atividade que constroem para as crianças e devem se perguntar o que exatamente está sendo alcançado.

À medida que as crianças começam a trabalhar com depoimentos de sobreviventes em um ambiente de aprendizagem construtivo, os ganhos de aprendizado são consideravelmente maiores, e um caminho para a conexão pessoal é estabelecido.

Não se trata apenas de dizer a elas "Vamos falar sobre essas pessoas diferentes", é dizer que vamos falar sobre elas e sobre como elas vivem suas vidas e então falar sobre as pessoas e conectar nossas vidas às delas.

Torna-se claro que o que é necessário na educação sobre a Shoah para o século XXI é uma abordagem ao ensino que enfatize a aprendizagem da história do evento, ao mesmo tempo que caminhe para uma análise de questões mais amplas do comportamento humano, escolha, estereótipos, bullying e preconceito. As discussões controversas, como um dos meios mais eficazes de envolver os estudantes nos estudos sociais, fornece-lhes, por fim, oportunidades reais de aprendizado e discussão baseados em evidências. Também dá aos alunos a chance de começar a formular sua visão de mundo baseada na história e nos dias atuais.

Claudia Lohrenscheit, diretora de educação em direitos humanos do German Institute of Human Rights, reafirmou que a educação sobre a Shoah tem dois objetivos: 0 primeiro deles seria o "[...] para que não se esqueça"; segundo, a educação é necessária para "[...] desenvolver competências para que nunca mais aconteça" (ZAPALSKA; HAUGLAND, 2016, p. 2). O que não significa que esta seja a única explicação possível. Já não se ensina a Shoah apenas "[...] para que não aconteça", afinal, fenômenos 
históricos não se repetem, e essa conclusão não é mais suficiente por si só. Assim, a educação sobre a Shoah, além de demonstrar a necessidade em se tomar decisões individuais, deve ser também uma ferramenta para ensinar a democracia e atos de responsabilidade. Como reconhece Lévinas (2007), é imprescindível que saibamos superar uma situação de isolamento e superioridade dominante para que possamos chegar ao outro lado, ir além do ser, despojar-se de si próprio em reconhecimento ao apelo do outro, educando para alteridade.

É amplamente reconhecido que um meio aceitável de ensinar história nas escolas do ensino fundamental e médio é através do uso de múltiplas perspectivas. Múltiplas perspectivas fornecem voz a vários grupos que experimentaram os mesmos eventos da história. Esses pontos de vista variados têm implicações ricas para o aprendizado dos alunos; ao projetarmos tais lições, podemos começar a evitar os "perigos da história". Isso nos move de uma visão míope da história para uma abordagem pluralista. Além disso, é necessário ir além da história abrangente de um grupo e começar uma análise da experiência individual de um determinado evento. Essa tática permite que os discentes comecem a se envolver com as nuances da história e façam sentido sobre o impacto de vários fatores, como política, comportamento social e economia.

O foco na história individual leva a uma sociedade menos apática. A história real acontece nas casas e nas ruas do mundo. A educação baseada em testemunhos fornece uma porta de entrada para que as pessoas possam ouvir como podem ser perseguidas por várias razões, muitas das quais são relevantes na sociedade atual. São lições para além do que foi a Shoah, são discussões sobre valores e convivência, permitindo que o aluno saia da totalidade do ser em si mesmo e se abra à exterioridade, ao outro. Verônica Kovacic (2017) destaca que educar é como a sociedade cria consciência de respeito, convivência e valores. É por meio desta que os relatos de sobreviventes fazem sentido para educar. Os discursos analisados desses passados traumáticos nos permitem construir um futuro possível, através do diálogo, com mais respeito, justiça e vivência (KOVACIC, 2017).

Use Your Voice ${ }^{8}$ é mais uma lição proposta pela USC Shoah Foundation que traz perspectivas de quatro homens e mulheres judeus que viveram na Alemanha e na

8 USC SHOAH FOUNDATION. Use Your Voice. Disponível em: https://iwitness.usc.edu/sfi/activity/detail. aspx? ?activityid=2533. Acesso em: 2 jan. 2019. 
Polônia durante a década de 1930. Eles falam sobre o preconceito que experimentaram de outros indivíduos bem como do governo nazista. Os objetivos dessa lição trazem como questões centrais discussões sobre o significado e as manifestações do preconceito, os efeitos desses comportamentos naqueles a quem o preconceito é dirigido e discussões sobre responsabilidade individual e as consequências de nossas ações. Sendo dividida em quatro seções: considerar, recolher, construir e comunicar; inicia-se a lição tratando de discutir os significados do termo "preconceito" e dividindo experiências possivelmente experimentadas pelos estudantes.

O material segue analisando o termo "bullying", associando-o a um comportamento agressivo indesejado entre crianças em idade escolar que envolve um desequilíbrio de poder real ou percebido, sendo um comportamento repetido, ou com potencial de ser repetido. A intenção não é comparar a Shoah com o bullying; desde o início, o material adverte:

\begin{abstract}
[...] é importante notar que o Holocausto não é como o bullying. Tampouco a experiência de vítimas ou sobreviventes do Holocausto era igual ao tipo de bullying que você ou alguém que você conhece possa ter experimentado. É importante ter em mente que, dentro das experiências individuais durante o Holocausto, há muitos exemplos de bullying, mas isso é apenas parte da história maior que deve ser contada dentro do contexto mais amplo.
\end{abstract}

Entretanto, sabe-se que o preconceito pode levar ao assédio moral. Quando alguém não gosta de outra pessoa com base na raça, etnia, crença religiosa ou algum outro aspecto de sua identidade, gera um sentimento de discriminação.

Paul Johnson (1989, p. 37) escreveu que, se o "[...] anti-semitismo é uma variedade de racismo, é uma variedade muito peculiar, com muitas características únicas. É tão peculiar que merece ser colocado em uma categoria bem diferente". Johnson (1989) chama o antissemitismo de "doença intelectual". O antissemitismo tem mais de dois mil anos e é o resultado da criação do cristianismo e da ascensão do capitalismo (ZAPALSKA; HAUGLAND, 2016). Por outro lado, o racismo é um fenômeno novo, que se originou durante o colonialismo. Embora seja feita essa distinção, deve-se observar um ponto importante: esses sentimentos crescem a partir de uma forma maior de discriminação. Assim, os mecanismos por trás deles são os mesmos. No entanto, é importante reconhecer que essas são ideologias diferentes, que devem ser comunicadas

Educação \& Formação, Fortaleza, v. 5, n. 13, p. 195-214, jan./abr. 2020 DOI: https://doi.org/10.25053/redufor.v5i13.1123 
aos alunos, a fim de evitar comparações simplificadas, mas para torná-los conscientes das diferenças que criam preconceitos. E a Shoah, como tema de estudo, tem a capacidade de nos mostrar esses aspectos da condição humana.

Durante a lição Use Your Voice, os testemunhos de Esther Clifford e David Faber chamam a atenção. Nascida em Munique, Alemanha, em 1920, Ester Clifford e sua família foram deportados para a Polônia em 1938, onde ela foi separada de sua família. Ester conta que em 1934 publicou-se um artigo chamado "Die Stürmer Zeitung" (sic: "Der Stürmer") Jornal Stormtrooper. O conteúdo do artigo, que estava engessado em todas as lojas que vendiam jornais, tinha rostos de pessoas com narizes longos e saliva saindo da boca (espumando) - típica referência ao povo judeu na Alemanha daquela época -, os quais estavam olhando para as crianças gentias, olhando com avidez o dinheiro que as crianças tinham nas mãos, como se quisessem roubar o dinheiro dessas crianças. $O$ artigo contava ainda histórias terríveis sobre médicos judeus tentando injetar medicação venenosa nos gentios. Ester afirma ainda que, enquanto ia à escola, todos liam o artigo e que, ao chegar ao colégio, ela não conseguiu participar da aula.

O testemunho de David Faber, nascido em 1926, em Nowy Sacz (Polônia), filho de uma família judia ortodoxa, conta que na escola os estudantes católicos ocasionalmente atiravam pedras nele por causa de sua identidade religiosa. Após a invasão alemã da Polônia em $1^{\circ}$ de setembro de 1939, David e sua família fugiram para Tarnów, na Polônia. Ele foi o único sobrevivente de dois tiroteios nazistas em Tarnów. Fez trabalhos forçados no campo de concentração de Putskow, na Polônia, e foi encarcerado em Auschwitz II-Birkenau, Bergen-Belsen, Buchenwald, Glesch, Jawischowitz, Mittelbau-Dora e Szebnie. Durante seu relato, David conta:

\footnotetext{
Certa vez, eu estava em uma rua, em uma rua muito movimentada com tráfego - tráfego muito pesado -, e eu estava esperando para atravessar a estrada. Um garoto estava me empurrando e me empurrava dizendo: 'Maldito judeu', em polonês. Finalmente ele me derrubou. Como a pista estava movimentada, ele me derrubou no meio dos carros. Havia uma mulher gritando: 'Por que alguém não chama uma ambulância? O menino precisa ser levado (referindo-se a mim), ele está em péssimas condições'. Então, outro homem, que estava do lado gritando, disse: 'Bem, é um 'Zyd', é um judeu. Não importa, deixe-o morrer'.
}

O estereótipo que havia sido criado sobre o povo judeu contribuiu para o avanço da política genocida que foi instaurada durante o Nazismo. Embora muitas pessoas que 
não testemunham o preconceito todos os dias possam pensar que é um problema do passado, aqueles que são alvos conhecem a triste verdade. As normas sociais e os contextos culturais desempenham um papel significativo nos tipos de preconceito que uma pessoa pode ter. $\mathrm{O}$ racismo se figurou proeminentemente durante séculos. Há vários exemplos atuais de que o preconceito contra judeus, por exemplo, ainda existe, bem como outros tipos de intolerância. Um estudo recente do FBI comprovou que os crimes de ódio nos EUA cresceram 17\% no último ano, especialmente contra negros e judeus (BBC NEWS BRASIL, 2018). Órgãos oficiais registraram 7.175 crimes de ódio, motivados por questões raciais, étnicas e de ascendência. Na França, o antissemitismo cresceu 69\% em 2018, já nos nove primeiros meses do ano (RFI, 2018). No Brasil, somente na grande São Paulo, houve aumento de $65 \%$ de crimes raciais registrados em 2018 (ARCOVERDE; PRADO, 2018).

Existe uma razão para tratarmos esse assunto em sala de aula. A Shoah representa o extremo até onde o ser humano pode chegar movido pelo preconceito. $O$ genocídio é a expressão máxima do ódio e da violência contra um grupo de pessoas. Sendo assim, a Shoah teve raízes em atitudes e comportamentos que vemos ao nosso redor todos os dias. É quando essas práticas se manifestam em seu extremo que o genocídio pode ocorrer, é o último passo em um continuum de ações tomadas por aqueles que hierarquizam a raça humana. Vêm a discriminação, o tratamento de certos grupos de pessoas de maneira diferente, 0 isolamento, a perseguição, seguidos pela desumanização, podendo chegar ao extremo da violência. Entender a natureza do preconceito, o uso de bodes expiatórios, estereótipos e discriminação é o primeiro passo no combate a essas práticas.

A lição ainda segue propondo a criação de um cartaz pelos alunos que thes diga sobre o significado do preconceito, seus efeitos e perigos, fazendo ainda uma conexão com suas vidas e experiências. Busca-se, assim, confrontar essas diferentes apresentações do passado na escola, pois, com a ampliação dos horizontes do mundo, nossas diferentes visões do passado tornaram-se, mais do que nunca, um dos fatores em conflito. Nossa visão de outros povos, ou de nós mesmos, reflete a história que nos é ensinada ainda quando crianças. Essa história nos marca para a vida. Sua representação, que é para cada um de nós uma descoberta do mundo, do passado das sociedades, abrange todas as nossas opiniões passageiras ou permanentes, de modo 
que os traços de nosso primeiro questionamento, nossas primeiras emoções, permanecem indeléveis. São esses vestígios que devemos conhecer ou redescobrir.

Segundo Ferro (1995), independentemente de sua cientificidade, a história exerce com efeito uma dupla função: terapêutica e militante. Em épocas diferentes, a "causa" desta missão mudou, mas não o seu significado. Idealmente a história testa criticamente a memória e se prepara para uma tentativa mais extensa de trabalhar em um passado que não passou. O ensino histórico deve, portanto, visar uma compreensão global dos fenômenos históricos e uma avaliação da relação entre problemas particulares (cidades, regiões, países) e o curso geral da história. Sendo assim, testemunhos orais tornaram-se centrais para a escrita da história nos últimos anos. As histórias em quadrinhos e filmes, por exemplo, valem-se de depoimentos ou, pelo menos, de tipos de narração que são inspirados a partir deles.

O medo de morrer junto com os sobreviventes da memória da Shoah, podendo ficar num espaço vazio, bem como ver ressurgir dos escombros a possibilidade do fascismo, é o que dá gás ao avanço dessa história oral. "Foi preciso ver-se frente a frente com o retorno ao terror para fazer muitos buscarem coragem, e forças, para se dedicarem à tarefa de fazer o passado reviver sobre o papel... para além da dor, a vergonha e a discriminação" (SILVA, 2013, p. 51).

É importante lembrar que o trabalho com testemunho não deve implicar generalizações do evento (KOVACIC, 2017), afinal, é apenas uma parte da história. Assim como o entendimento da Shoah em sua totalidade não deve ser descartado, pelo contrário, somado a isso é que se devem discutir questões voltadas à alteridade, às diferenças, ao preconceito. Devemos ser capazes de não somente recordar, mas transformar esse passado numa esperança para o futuro (KOVACIC, 2017). É a partir daí que humanizamos o processo, tornamos ele possível de ser entendido. O que não significa, portanto, tentar enquadrá-lo no âmbito da normalidade, mas reconhecê-lo como um fenômeno que, apesar de fugir da compreensão do bom senso, de um "[...] agir normal, quem pode contar deve fazê-lo" (VENEZIA, 2010, p. 70), na tentativa de transmitir o incomum à compreensão e experiência humanas.

Educação \& Formação, Fortaleza, v. 5, n. 13, p. 195-214, jan./abr. 2020 DOI: https://doi.org/10.25053/redufor.v5i13.1123 


\section{CONCLUSÃO}

A essência da Shoah é difícil de entender, assim como muitas das histórias humanas relacionadas a ela. Aprender sobre esse evento, através da documentação histórica combinada com a audição de testemunhos de pessoas que realmente experimentaram esse período, ajuda a tornar esses eventos mais tangíveis e realistas. Sendo assim, torna-se uma tarefa profundamente desafiadora a partir de várias perspectivas acadêmicas e intelectuais. Enfrentar a Shoah, portanto, significa tentar compreender os seres humanos e a maneira como eles lidaram com situações extremas e com profundos dilemas éticos. A história da Shoah é, em primeiro lugar, uma história humana. Qualquer discussão sobre suas vítimas, seus perpetradores ou aqueles que permaneceram e assistiram deve tentar entender o ser humano envolvido. É a microhistória, a história de uma pessoa contada a partir de uma perspectiva específica e subjetiva.

Usar o testemunho na sala de aula é uma maneira de personalizar a história da Shoah para os alunos. Isso pode ajudá-los a entender que, embora fosse um trauma coletivo, era diferente para cada indivíduo que vivia naquele período de tempo. Toda experiência foi temperada por lugar, tempo e circunstância pessoal. Sobrevivência dependia de muitos fatores, a maioria dos quais inquantificáveis. É então que chegamos no ponto central do papel da educação: "educar para alteridade". A alteridade é uma construção social que explica as identidades sociais. Pensar na identidade social como um reflexo de como os indivíduos e grupos internalizam as categorias sociais estabelecidas - cultura, raça, etnia, classe - dentro das sociedades. Sendo assim, desenvolver uma reflexão sobre a função da alteridade, da responsabilidade e do agir ético, num sentido mais amplo, torna-se crucial nos debates acerca da Shoah. Faz-se necessário assegurar esses princípios de humanidade, já que as in-humanidades do nosso tempo - que vão da violência mais velada ao horror - estão se tornando cada vez mais possíveis. 


\section{REFERÊNCIAS}

ARCOVERDE, L.; PRADO, G. Número de casos de crimes raciais registrados cresce 65\% na Grande SP em 2018. GloboNews e G1 SP, jul. 2018. Disponível em: https://g1. globo.com/sp/sao-paulo/noticia/2018/07/18/numero-de-casos-de-crimes-raciais-registra dos-cresce-65-na-grande-sp-em-2018.ghtml. Acesso em: 2 jan. 2019.

BAUER, Y. Reflexiones sobre el Holocausto. Israel: Nativ, 2008.

BBC News Brasil. FBI: crimes de ódio nos EUA crescem e atingem principalmente negros e judeus. BBC News Brasil, 13 nov. 2018. Disponível em: https://www.bbc.com/ portuguese/internacional-46202965. Acessado em: 2 jan. 2019.

DAVIES, I. Teaching the Holocaust: educational dimensions, principles, and practice. London: Continuum, 2000.

DURKHEIM, É. A educação moral. Rio de Janeiro: Vozes, 2008.

ECHOES AND REFLECTIONS. Echoes and reflections: leaders in Holocaust education. New York: Anti-Defamation League, 2005.

ENDACOTT, J. L.; BROOKS, S. An updated theoretical and practical model for promoting historical empathy. Social Studies Research \& Practice, v. 8, n. 1, p. 41-58, 2013.

FERRO, M. Cómo se cuenta la historia a los niños del mundo entero. Ciudad de México, DF: Fondo de Cultura Económica, 1995.

JOHNSON, P. História dos judeus. Rio de Janeiro: Imago, 1989.

KOSELLECK, R. Futuro passado: contribuição à semântica dos tempos históricos. Rio de Janeiro: Contraponto, 2006.

KOVACIC, V. Conocer, compreender y recordar: recursos para enseñar el HolocaustoShoá y otros procesos genocidas. Buenos Aires: Prometeo, 2017.

LÉVINAS, E. Ética e infinito. Lisboa: 70, 2007.

RFI. Atos antissemitas têm aumento de 69\% na França em 2018. G1, 11 nov. 2018. Disponível em: https://g1.globo.com/mundo/noticia/2018/11/09/atos-antissemitas-temaumento-de-69-na-franca-em-2018.ghtml. Acesso em: 2 jan. 2019.

SCHWEBER, S. Making sense of the Holocaust: lessons from classroom practice. New York: Teachers, 2004.

SILVA, F. C. T. A História na primeira página. Rio de Janeiro: Multifoco, 2013.

Educação \& Formação, Fortaleza, v. 5, n. 13, p. 195-214, jan./abr. 2020 DOI: https://doi.org/10.25053/redufor.v5i13.1123 
VENEZIA, S. Sonderkommando: no inferno das câmaras de gás. Rio de Janeiro: Objetiva, 2010.

ZAPALSKA, A. M.; HAUGLAND, E. W. Learning the lessons of the Holocaust: a case study of the USA Coast Guard Academy. Journal of Defense Management, v. 6, 2016.

\section{Alyne Nathálier da Silva Palmeira (Brasil, Pernambuco, Recife) \\ Universidade de Pernambuco (UPE)}

Graduada pela Universidade de Pernambuco (UPE) no curso de licenciatura plena em História Campus Mata Norte. Vinculada ao Grupo de Estudos em História Sociocultural da América Latina (Gehscal), pela linha de pesquisa História do Tempo Presente (HTP), que tem por coordenador o professor doutor Karl Schurster Veríssimo de Souza Leão. Atualmente desenvolve pesquisas na área de Educação, com ênfase no Ensino de História de Eventos Traumáticos, como a Shoah. Lattes: http://lattes.cnpq.br/7456416035778908.

E-mail: alynenathalier@hotmail.com.

\section{Karl Schurster (Brasil, Pernambuco, Recife) \\ Universidade de Pernambuco (UPE)}

Doutor em História Comparada pela Universidade Federal do Rio de Janeiro (UFRJ), com estágio de pesquisa na Freie Universität Berlin. É professor permanente do Programa de Pós-Graduação em Educação da Universidade de Pernambuco (UPE) e do ProfHistória da Universidade Federal de Sergipe (UFS), colaborador. Atualmente é diretor de relações internacionais e exerce a coordenação científica da Edupe/UPE.

Lattes: http://lattes.cnpq.br/9572701361201130.

E-mail: karl.schurster@gmail.com.

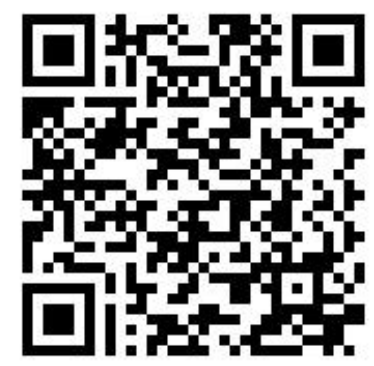

Recebido em 26 de junho de 2019.

Aceito em 03 de outubro de 2019.

Educação \& Formação, Fortaleza, v. 5, n. 13, p. 195-214, jan./abr. 2020 DOI: https://doi.org/10.25053/redufor.v5i13.1123 